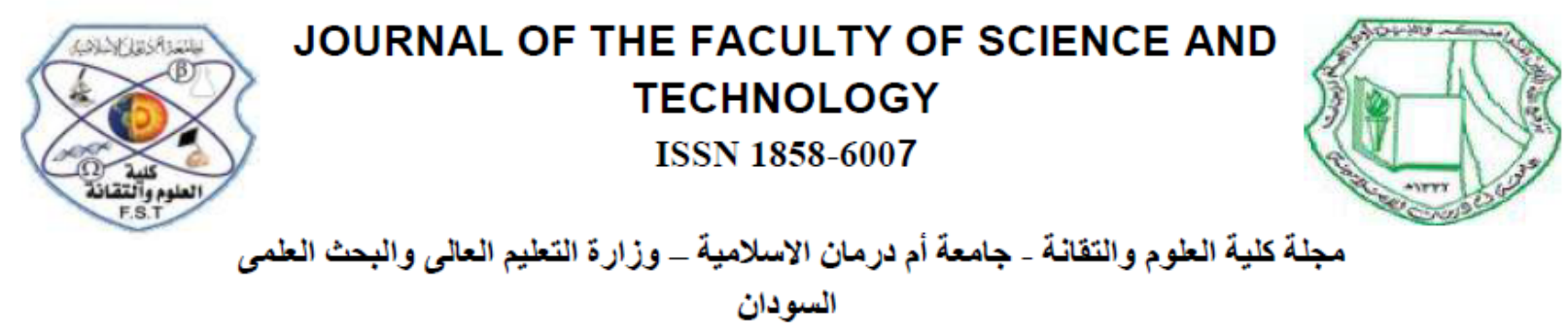

Research article

\title{
Effect of Emulsion in Sudanese Crude Oil PalougeField ,Melute Basin
}

TagelsirAwad Ahmed Digno,

Faculty of Engineering Sudan University of Science and Technology Khartoum, Sudan

e-mail: tagelsir729@gmail.com

\section{ABSTRACT}

The study was conducted inPalouge Field in Malute Basin Block $3 \& 7$ located in the Republic of South Sudan This paper discusses problems related to oil emulsions that havebeen encountered in Palouge Field. Oil samples collected from 17 Oil Gathering Manifold (OGM), viscositiesranges from $106 \mathrm{cP}$ to over $8159 \mathrm{cP}$ (@ 50 $\mathrm{C}$ and API gravities rangedfrom 13 to 25. Emulsion from 2 up to 33 and watercut form (7\% water cut to over 77\%), Pour Point 30 to $42^{0}$. These propertiesprovide an interesting case of operational problems in oil waterseparation. The main causes of emulsionformation in the investigated fields were watercut,temperature, shear, Pour Point, demulsifier dosage andmixing different crudes. The results show a strong correlation ofPour Point (Paraffinic content which lead to stabilized emulsion)in the crude oil with the water-oilseparation index or emulsion tightness. Recommendations are made for reducing and optimizingdemulsifier dosage by adding chemical additives , and further comprehensive study should be done to determine the compounds which lead to stabilized emulsion for example Naphthenic compound and Asphaltenic.

Keywords: demulsifier, Palouge Oilfield, formation water,Environmental concerns

\section{1- INTRODUCTION}

Water-in-oil emulsions are formed during the production of crude oil. The stability of the emulsion is ranging from a few minutes to years depending on the nature of the crude oil and to some extent the nature of water(Daaou, M., Bendedouch, D, 2012). A recent report has suggested that an equivalent volume of water accompanied the daily production of some 60 million barrels 
of crude oil Under the production conditions, a proportion of this water can become intimately dispersed throughout the crude oil as small droplets.Emulsions (Fortuny, Met al 2007) are undesirable because the volume of dispersed water occupies space in the processing equipment and pipelines, increased operating and capital costs. Moreover, the characteristics and physical properties of oil change significantly upon emulsification. The density of emulsion can increase from 800 $\mathrm{kg} / \mathrm{m}^{3}$ for the original oil to $1030 \mathrm{~kg} / \mathrm{m}^{3}$ for the emulsion. The most significant change is observed in viscosity, which typically increases from a few $\mathrm{mPa} \cdot \mathrm{s}$ or less to about $1000 \mathrm{mPa} \cdot \mathrm{s}$.

Emulsion resolution is therefore an important element in handling the petroleum, from the time it is produced until it enters the refining process. In order to minimize the production problems related with crude oil emulsions and environmental concerns, petroleum operators need to prevent their formation or to break them .In some cases when the formation of emulsions is a result of poor operation practices, it is possible to prevent emulsion formation. Nevertheless, in many instances emulsion formation is predictable. The exclusion of water during recovery from the oil wells and prevention of agitation is difficult to realize, and emulsions must be treated.

The treatment of water-in-crude oil emulsions involves the application of thermal, electrical, chemical process or their combinations. Thermal method or heat treatment in emulsion breaking is usually based on the overall economic picture of a treating facility. Excess heat is not supplementary when it is more commercial to add chemical or set up electrostatic heat. Temperatures are not high enough to significantly rise up water solubility in a particular crude oil, and high temperatures do not cause large amounts of asphaltenes (Daaou,M. et al2009)(Gafonova, O. V. et al.2000),(Groezin, H. et al .2007) to become insoluble in the crude oil andform an interface pad (Honse, S. O.et al. 2012).

Polymeric demulsifiers (Kelland, M. A. 2009) are also the most common demulsifiers (Ramalho, J. B. V. S.,et al. 2010) used to break water in oil emulsion. The polymeric demulsifiers (Lucas, E. F., et al 2009) are capable of adsorbing at the oil or water interface by displacing the interfacial film. Interfacial active fraction presence in the oil posses a sufficient numbers of functional groups that can penetrate into the oil or water interface, and form an interfacial layer which can be 
broken by demulsifiers (Mat, H. B., 2006).(Wang, X. Y., Alvarado, V. J 2009)(Al-Yaari, M. et al. 2015).

In order to devise optimum treatment for water-in-oil emulsions by usingchemical treatment method, it is vital to understand how they are stabilized anddestabilized the emulsion. Therefore, screenings of demulsifiersare very importantin deciding the most effective demulsifiers in breaking the emulsion system. Thisresult will lead to demulsifiers formulation for treating crude oil emulsion. The objective of this study is to evaluate the emulsion by using different types of Demulsifiersand Reverse Demulsifier using Bottle test method in the Laboratory and Field trail techniques.The bottle test is used to assist in the selection of a demulsifier which will most effectively resolve the emulsion produced by a given well or production system..

\section{2-METHODOLOGY}

\section{Materials and Methods}

Samples of crude oil were collected from 17

Oil gathering manifolds OGMs flow lines in (Test-1) 17 samples of $500 \mathrm{ml}$ clean plastic bottle were analyzed for water cut and emulsion (ASTM, D 96-88 1998). Another samples for bottle test to determine the optimumvolume of chemicals to be injected through the line of crude oil for emulsion treatment (Test-2),17 samples using a stainless steel bomb permits sampling at produced fluid pressure thus minimizing loss of light ends and gas. A representative samplewithout any chemicals added such as demulsifierscorrosion inhibitors, paraffins, and finally fresh to prevent emulsion stabilization was tested.

\section{Reagents:-}

\section{Demulsifiers reagents collected from three companies:-}

1-PWP 916

2-PWP 718

3-ChampionX-80-29-A

Reverse Demulsifiers reagents collected from three companies

1-Dwell

2-Clariant

3-Champion

\section{3-RESULT AND DISCUSSIONS}

Crude oils are mainly consist of asphaltenes, resins and waxes. The presence of these agents results in the formation of stable emulsion. Stability is the persistence of an emulsion (Kumar, S.; Mahto, V. 2016) and presence of an interfacial film on the droplets to coalesce due to the present of interfacial active agents. As a result, the 
suspended droplets do not settle out, float and coalesce quickly.

Crude oil in the reservoir is found together with formation water. The stable emulsion (Akbari, S.,et al. 2015) resulted from the stress caused from the flow of crude oil and formation water. Emulsions create a lot of problems such as corrosion. For these reasons, crude oils must be treated by using demulsification process. There are four types of emulsions; W/O, O/W, W/O/W and $\mathrm{O} / \mathrm{W} / \mathrm{O}$.Demulsifere which to injected to the Ogms must be calculatedaccording to the OGMs production to avoid demulsifierover dose and the cost wise, the dose to be injected should be in liter per hour L/H .(Figure-1) represents OGMs water cuts $\%$ the volume of water cut ranged in between 7\% in Ogm 11 to $77 \%$ in Ogm 6, (Figure-2) Shows the Ogm emulsion \% the emulsion volume ranged in between 2\% in Ogm 4 up to $33 \%$ in Ogm 3 ,(Figure3) Demonstrate the emulsion volume \%, water cut \%and Demulsifier dose to be injected according to the Ogms production

The most widely used method in this treatment process is by using chemical demulsification. This process involves the use of chemical additives (demulsifiers) in order to accelerate the emulsion breaking process. The demulsifier adsorbs at the interfacial film, weaken the interfacial barrier and separate the water droplets. Bottle test method or jar test method is commonly used in developing a new formulation of demulsifiers composition and the results is read from the water separation level. To choose the most effective demulsifiers, screening process is used without considering the price of the demulsifiers. Basically, oil-soluble demulsifiers are more expensive compared to water-soluble demulsifiers. Table (2), shows the efficiency of the three product used in the field with the different separation performance $\%$ which ranged between $55 \%, 59 \%$, and $60 \%$.

Table (3) represent the visual test regarding the interface, water quality and water drop speed which ranged from sharp, clear tofast .Table (4)shows the difference in separation performance \%for reverse demulsifier of the chemical products companies, which ranged from $80 \%$ to $92 \%$

Regarding the study of Demulsifierswhich has four main actions: a) Strong attraction to the oil-water interface. They must displace and/or neutralize the emulsifying agents (Nesterenko, A.,et al 2014) already on the droplet interface, b) Flocculation. They must neutralize any 
repulsive electrical charges between the dispersed drops and so allow the drops to touch, c)Coalescence. They must permit small droplets to combine intodrops large enough to settle; this requires that the film surrounding and stabilizing the droplets be ruptured) solids wetting. They must prevent fines at the droplet interface from physically blocking coalescence. Clays,

(Table-1)The major types of demulsifier chemicals can be characterized as follows

\begin{tabular}{|c|c|}
\hline Type & Characterization \\
\hline Esters & $\begin{array}{l}\text { - good dehydrators, drop } \\
\text { water out slowly, } \\
\text { - subject to overdosing, } \\
\text { - Glycol esters reduce o/w } \\
\text { interface pad }\end{array}$ \\
\hline $\begin{array}{l}\text { Di- } \\
\text { epoxides: }\end{array}$ & $\begin{array}{l}\text { - excellent dehydrator, } \\
\text { - Little effect on water drop }\end{array}$ \\
\hline Urethanes: & $\begin{array}{l}\text { - good dehydrator, do not } \\
\text { effect water drop }\end{array}$ \\
\hline Resins: & $\begin{array}{l}\text { - speed water drop, will } \\
\text { water-wet solids, } \\
\text { - fair to good dehydrators, } \\
\text { - oxyalkylated-acid-catalyzed } \\
\text { resins give good quality, clean } \\
\text { separated water, } \\
\text { - base-catalyzed resins give } \\
\text { drier oil }\end{array}$ \\
\hline $\begin{array}{l}\text { Polyalkylen } \\
\text { eGlycols }\end{array}$ & $\begin{array}{l}\text { - poor dehydrator, do not } \\
\text { drop water quicklyrequire }\end{array}$ \\
\hline
\end{tabular}

Demulsifier chemicals should be injected as early as possible e.g., at the wellhead or down hole. This allows more time for the chemicals to work, can also prevent possible downstream emulsion drilling mud, and iron sulfide fines can be water wet so that they leave the film interface and migrate into the water droplet. Asphaltenes and waxes can be dissolved or oil wet to disperse them intothe continuous crude phase. The composition is differ from company to another which composed of polymers the monomer are shown in (table- 1).

\begin{tabular}{|c|c|}
\hline & blending for most applications \\
\hline Sulfonates: & $\begin{array}{l}\text { - can resolve virtually any } \\
\text { emulsion, } \\
\text { - good wetting and water } \\
\text { drop abilities, } \\
\text { - overdosing does not cause } \\
\text { o/w emul } \neg \text { sion, but cancause } \\
\text { FeS particles to drop out }\end{array}$ \\
\hline $\begin{array}{l}\text { Polyestera } \\
\text { mines }\end{array}$ & $\begin{array}{l}\text { - extremely surface active, } \\
\text { dehydrate at low dosages, } \\
\text { produce sharp o/w inter } \neg \text { face }\end{array}$ \\
\hline $\begin{array}{l}\text { Oxyalkylat } \\
\text { ed }\end{array}$ & $\begin{array}{l}\text { - good wetting agents, used in } \\
\text { blends, }\end{array}$ \\
\hline phenols & $\begin{array}{l}\text { - reduce interface pad build- } \\
\text { up, } \\
\text { - fair to poor demulsifiers }\end{array}$ \\
\hline $\begin{array}{l}\text { Oxyalkylat } \\
\text { ed }\end{array}$ & - excellent emulsion breakers \\
\hline polyamines & - retard water drop \\
\hline $\begin{array}{l}\text { Alkanolami } \\
\text { nes }\end{array}$ & $\begin{array}{l}\text { - speed water drop, fair } \\
\text { total performance }\end{array}$ \\
\hline
\end{tabular}

formation, and allows different chemicals to be used for problem wells. Injecting demulsifiers ahead of a pump ensures adequate mixing and minimizes emulsion formation by the pump. Mild mixing, 
such as in pipe flow at design velocities, can accelerate chemical dispersion and flocculation of water drops. However, intense agitation e.g., centrifugal pumps promotes emulsion formation.

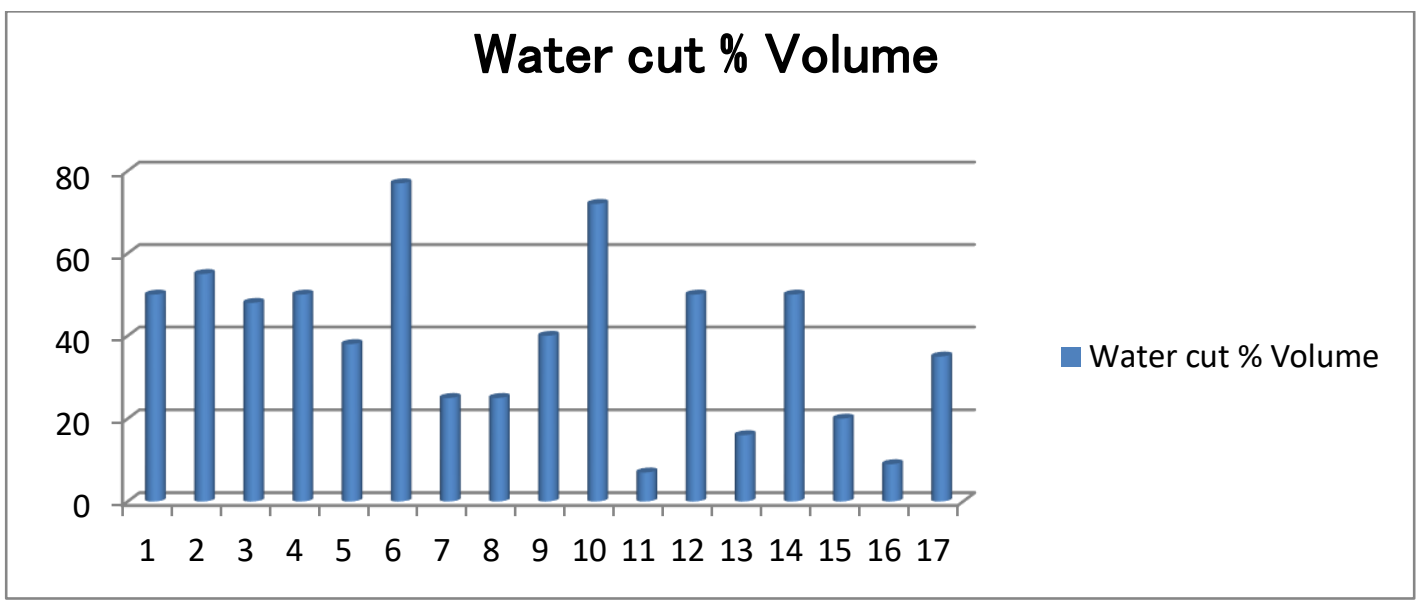

Figure (1) Water cut\%Volume from 17 OGMs

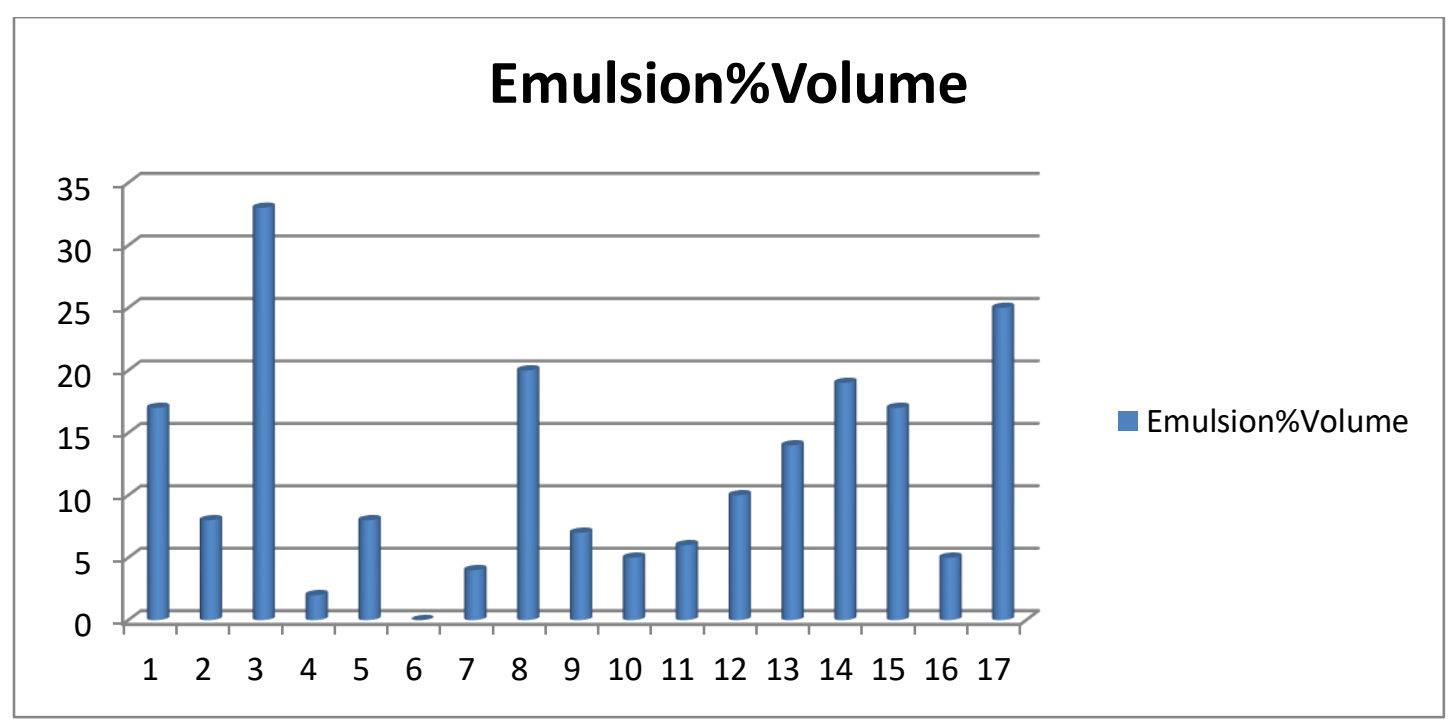

Figure (2)Ogm Emulsion\% Volume

Ogm : Oil gathering Manifold

FPF : Field process Facility 


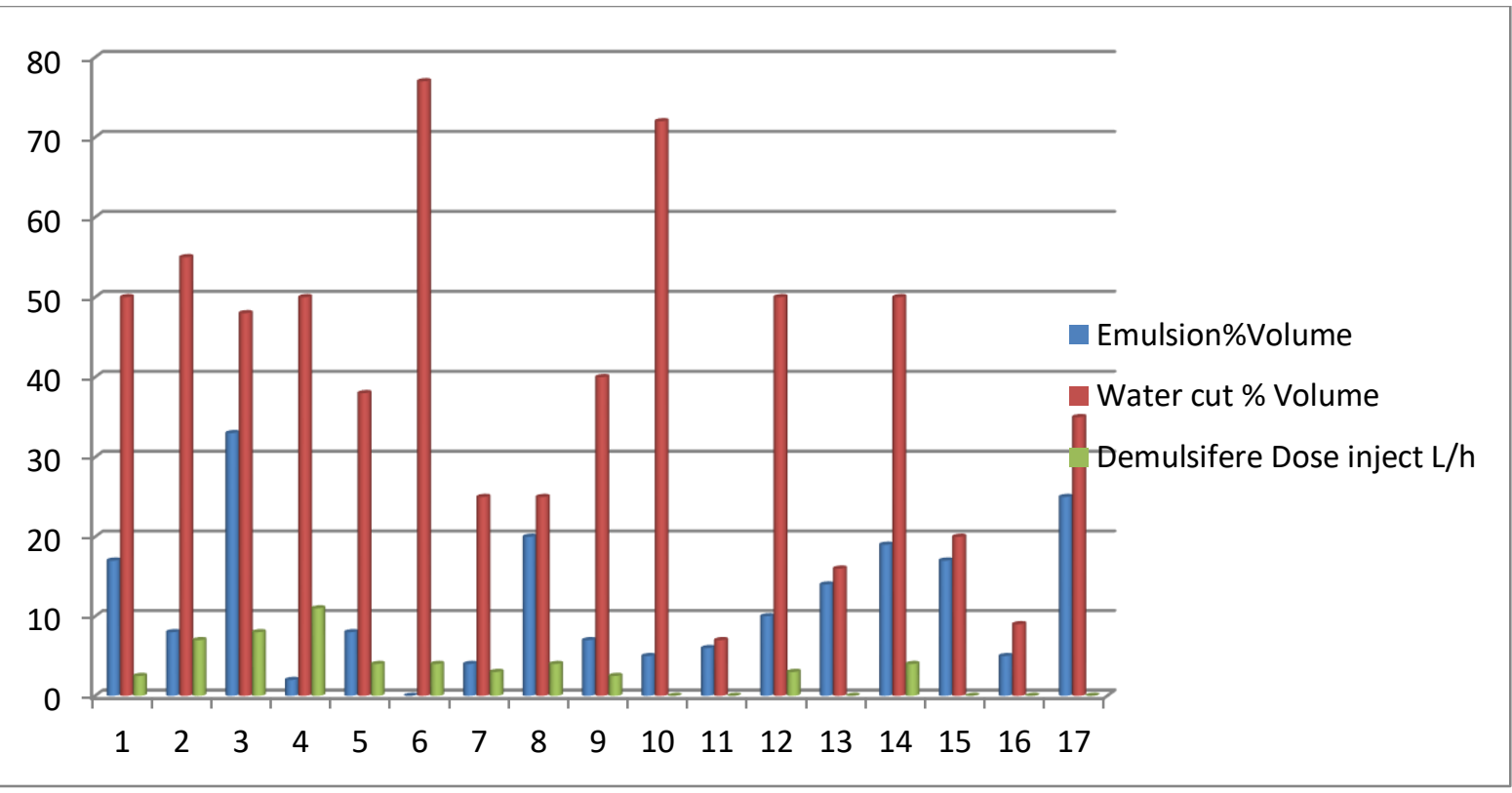

Figure (3) Emulsion \%Volume, Water Cut\% Volume and Demulsifier Dose inject

Table(2) 3ree Companies to show difference Separation Performance\%

\begin{tabular}{|c|c|c|c|c|}
\hline Company Product & PWP & PWP & Champion & Blank \\
\hline Results & 916 & 718 & $X-80-29-A$ & \\
\hline Separated Water \% after 15 min @ $75^{\circ} \mathrm{C}$ & 0.2 & 0.2 & 0.2 & 0.0 \\
\hline Separated Water $\%$ after 30 min @ $85^{\circ} \mathrm{C}$ & 3.0 & 0.4 & 0.6 & 0.2 \\
\hline Separated Water \% after $60 \min @ 80^{\circ} \mathrm{C}$ & 11.0 & 3.0 & 4.0 & 1.8 \\
\hline Separated Water \% after 90 min @ $80^{\circ} \mathrm{C}$ & 12.0 & 7.0 & 9.0 & 4.0 \\
\hline Separated Water \% after 120 min @ $80^{\circ} \mathrm{C}$ & 13.0 & 11.0 & 12.0 & 6.0 \\
\hline Top Cut BS\&W after 120 min & $9 \%$ & $9 \%$ & $8 \%$ & $17 \%$ \\
\hline Total Water Cut in the Bottle \% & 22 & 20 & 20 & 23 \\
\hline Separation Performance \% & $59.0 \%$ & $55.0 \%$ & $60 \%$ & $26 \%$ \\
\hline
\end{tabular}


Table(3) 3ree Companies to show Comparison in interface, water quality and water drop speed

\begin{tabular}{|c|c|c|c|c|}
\hline Company Product & PWP & PWP & Champion & Blank \\
\hline Results & 916 & 718 & X-80-29-A & \\
\hline \multicolumn{5}{|c|}{ Visual Test } \\
\hline Interface & Sharp & sharp & Sharp & \\
\hline Water quality & Clear & Clear & Clear & \\
\hline Water drop speed & Very Fast & Not Fast & Fast & \\
\hline
\end{tabular}

Table (4) 3ree Companies to show difference Separation Performance\% for Reverse Demulsifere

\begin{tabular}{|c|c|c|c|c|}
\hline Company Product & $\begin{array}{c}\text { Reverse } \\
\text { Demulsifier }\end{array}$ & $\begin{array}{c}\text { Reverse } \\
\text { Demulsifier \#1 }\end{array}$ & Reverse Demulsifier \#2 & Blank \\
\hline Results & Champion & Dwell & Clariant & $* * *$ \\
\hline $5 \min$ & $\mathbf{0 . 0}$ & $\mathbf{0 . 0}$ & 0.0 & 0.2 \\
\hline $10 \mathrm{~min}$ & 0.2 & $\mathbf{0 . 0}$ & $\mathbf{0 . 0}$ & 0.4 \\
\hline $15 \mathrm{~min}$ & 1.4 & $\mathbf{0 . 0}$ & $\mathbf{0 . 0}$ & 2.0 \\
\hline $20 \mathrm{~min}$ & 2.0 & 0.0 & 0.0 & 3.0 \\
\hline $30 \mathrm{~min}$ & 6.0 & 0.0 & $\mathbf{0 . 0}$ & 6.0 \\
\hline $60 \mathrm{~min}$ & 25 & 0.0 & 10 & 30 \\
\hline $120 \mathrm{~min}$ & 42 & 40 & 40 & 40 \\
\hline $180 \mathrm{~min}$ & 46 & 40 & 40 & 40 \\
\hline $\begin{array}{c}\text { Top Cut BS\&W after } \\
180 \mathrm{~min}\end{array}$ & 4 & 10 & 10 & 10 \\
\hline $\begin{array}{c}\text { Total Water Cut in } \\
\text { the Bottle \% }\end{array}$ & 50 & $\mathbf{5 0}$ & 50 & 50 \\
\hline $\begin{array}{c}\text { Separation } \\
\text { Performance \% }\end{array}$ & 92 & 80 & 80 & 80 \\
\hline
\end{tabular}




\section{4-CONCLUSIONS}

Crude oils are mainly consists of asphaltenes, resins and waxes. The presence of these agents results the formation of stable emulsion. Stability is thepersistence of an emulsion and presence of an interfacial film on the droplets tocoalesce due to the present of interfacial active agents.

Emulsions are characterized by the type of emulsion ( $\mathrm{W} / \mathrm{O}, \mathrm{O} / \mathrm{W}$, or multiple), nature of emulsifying agents present, BS\&W, droplet size and droplet-size distribution, bulk viscosity, and interfacial viscosity.

Emulsions are destabilized by increasing temperature, moderate agitation followed by gentle settling (i.e. residencetime), removing solids, and controlling emulsifiers The mechanisms involved in demulsification are flocculation, aggregation, and coalescence

The methods involved in emulsion breaking or demulsification are thermal, mechanical, electrical, and chemical. Experience and economics determine which methods are used, and to what degree, for emulsion treatment.

\section{ACKNOWLEDGMENTS}

I would like to thank Dr. Bashir Mohamed Elhassan Faculty of Engineering Khartoum University ,Sudan for his drive and commitment to help me reach my goal.

\section{5-REFERENCES}

Akbari, S., Abdurahman, N. H., and Fayaz, F. (2015).The influence of process parameters on stability of water-in-crude oil emulsion stabilized by span 80 . International Journal of Engineering Sciences and Research Technology, 4(5), pp. 526-534.

Al-Yaari, M.; Hussein, I. A.; Al-Sarkhi, A.; Abbad, M., Chang, F. Effect of water salinity on surfactant-stabilized water-oil emulsions flow characteristics. Experimental Termal and Fluid Science, v.64, p. 54-61, 2015.

Daaou, M., Bendedouch, D., Water pH and surfactant addition effects on the stability of an Algerian crude oil emulsion. Journal of Saudi Chemical Society, 16, 333337,(2012)

Daaou, M., Bendedouch, D., Bouhadda, Y., Vernex- Loset, L., Modaressi, A., Rogalski, M., Explaining the flocculation of HassiMessaoudasphaltenes in terms of structural characteristics of monomers and aggregates. Energy \& Fuels, 23, 5556- 5563 (2009).

Fortuny, M., Oliveira, C. B. Z., Melo, R. L. F. V., Nele, M., Coutinho, R. C. C., Santos, A. F., Effect of salinity, temperature, water content, and $\mathrm{pH}$ on the microwave 
demulsification of crude oil emulsions.Energy Fuels, 21, 1358-1364 (2007).

Gafonova, O. V., Role of asphaltenes and resins in the stabilization of waterinhydrocarbon emulsions. The University of Calgary, MSc. Thesis (2000).

Groezin, H., Mullins, O. C., Asphaltene Molecular Size and Weight by Timeresolved Fluorescence Depolarizarion. In: Mullins, O. C., Sheu, E. Y., Hammami, A., Marshall, A. G., (Eds.), Asphaltenes,Heavy Oils, and Petroleomics, Springer, New York, 2007, p. 17.

Honse, S. O., Ferreira, S. R., Mansur, C. R. E., Lucas, E. F., Gonzalez, G., Separation and characterization of asphaltenicsubfractions. Quimica Nova,35(10), 1991-1994 (2012).

Kelland, M. A., Production Chemical for the Oil and Gas Industry. CRC Press, New York, (2009).

Kumar, S.; Mahto, V. Emulsification of Indian heavy crude oil in water for its efficient transportation through offshore pipelines. Chemical Engineering Research and Design, v. 115, p. 34-43, 2016.https://doi.org/10.1016/j.cherd.2016.0 9.017

Lucas, E. F., Mansur, C. R. E., Spinelli, L., Queirs, Y. G. C., Polymer science applied to petroleum production. Pure and Applied Chemistry, 81(3) 473- 494 (2009).

Mat, H. B., Study on demulsifier formulation for treating Malaysian crude oil emulsion.PhD Thesis, Department of Chemical Engineering, Faculty of Chemical and Natural Resources Engineering, UniversitiTeknologi Malaysia (2006).

Nesterenko, A., Drelich, A., Lu, H., Clausse, D., and Pezron, I. (2014). Influence of a mixed particle/surfactant emulsifier system on water-in-oil emulsion stability. Colloids and Surfaces A: Physicochemical and Engineering Aspects, 457, pp.

49-57.

Ramalho, J. B. V. S., Lechuga, F. C., Lucas, E. F., Effect of the structure of commercial poly(ethylene oxide-b-propylene oxide) demulsifier bases on the demulsification of water-in-crude oil emulsions: Elucidation of the demulsification mechanism. Quimica Nova, 33(8) 1664-1670 (2010).

Wang, X. Y., Alvarado, V. J., Direct current electrorheologicalstability determination of water-in crude oil emulsions. Journal of Physical Chemistry, B 113, 13811-13816 (2009).

https://doi.org/10.1016/j.expthermflusci.201

$\underline{5.02 .001}$ 